\title{
Afetividade entre estudantes e sistema de cotas para negros
}

\author{
Maria da Penha Nery ${ }^{1}$ \\ Liana Fortunato Costa \\ Universidade de Brasília, Brasília-DF, Brasil
}

\begin{abstract}
Resumo: Este artigo versa sobre a afetividade presente entre estudantes cotistas e não-cotistas durante a vigência da política de cotas raciais na Universidade de Brasília. Trata-se de uma pesquisa qualitativa, com enfoque teórico da Socionomia de Jacob Levy Moreno. Os instrumentos foram um sociodrama e entrevistas semi-estruturadas. Participaram do sociodrama cinco estudantes, foram entrevistados três estudantes e um integrante de uma organização não-governamental. Os dados foram analisadas pela proposta da epistemologia qualitativa. Entre os estudantes universalistas observou-se indiferença em relação ao cotista e descaso em relação a questões raciais. Por parte dos cotistas houve uma autocobrança por excelente desempenho acadêmico para aplacar a discriminação gerada pelas cotas. Com relação aos processos identitários, houve predomínio do ocultamento da identidade e o temor de se expor no novo papel social. Conclui-se pela necessidade de criação de projetos psicossociais para efetivar a integração dos estudantes no contexto da política afirmativa.
\end{abstract}

Palavras-chave: afeição, política, negritude, sociometria.

\section{Affectivity among students and the system of quotas for black people}

\begin{abstract}
This study focused on affectivity existent between students favored by the quota system and regular students during the period in which racial quotas were adopted by the University of Brasilia. The theoretical reference of this qualitative study was the Jacob Levy Moreno's Socionomy. Sociodrama and semi-structured interviews were used. Five students participated in the sociodrama, three students and one individual from a non-governmental institution were interviewed. Data were analyzed through the qualitative epistemology. We observed that students who were regularly admitted at the university were indifferent to students who were favored by the quota system and disregarded racial issues. There was a high expectation among students admitted through the quotas system to exceed academic performance so to placate discrimination generated by such policy. In regard to identity processes, most students occulted their identity and feared being exposed to this new social role. We conclude that there is a need to create psychosocial projects to integrate students within the affirmative action context.
\end{abstract}

Keywords: affection, politics, negritude, sociometry.

\section{Afectividad entre estudiantes y sistema de cuotas para negros}

\begin{abstract}
Resumen: Este artículo versa sobre la afectividad presente entre estudiantes cuotistas y no-cuotistas durante la vigencia de la política de cuotas raciales en la Universidad de Brasilia. Se trata de una pesquisa cualitativa con enfoque teórico de la Socioeconomía de Jacob Levy Moreno. Los instrumentos fueron un sociodrama y entrevistas semiestructuradas. Los sujetos del sociodrama fueron cinco estudiantes y de las entrevistas fueron tres estudiantes e uno integrante de una organización no gubernamental. Los datos fueron analizados por la propuesta de la epistemología cualitativa. Con los estudiantes universalistas se observó la indiferencia en relación a los cuotistas y el desinterés para cuestiones raciales. Por parte de los cuotistas hay una autoexigencia por desempeño académico excelente para compensar la discriminación generada por las cuotas. Con relación a los procesos identitarios, predomina el ocultamiento de la identidad y el temor de se exponer en su nuevo papel social. Concluimos que es necesaria la creación de proyectos psicosociales para la efectiva integración de los estudiantes en el contexto de la política afirmativa.
\end{abstract}

Palabras clave: afección, política, negritud, sociometria.

O objeto desta pesquisa qualitativa é a afetividade vivida nas relações entre sujeitos universitários aprovados pelo sistema de cotas para o ingresso de negros na Universidade de Brasília (UnB) e sujeitos universitários aprovados pelo sistema universal. Cotista é o papel desempenhado pelo indivíduo que é aprovado no vestibular para a universidade por meio de sistema de cotas raciais, e universalista é o papel desempenhado pelo indivíduo que presta o vestibular optando pelo sistema universal.

Este artigo objetiva observar as interações afetivas dos sujeitos universitários envolvidos em um processo de inclusão socioracial; conhecer as significações nas interações

\footnotetext{
1 Endereço para correspondencia:

Maria da Penha Nery. SQSW 300, Bloco M, apto. 502. CEP: 70.673-046.

Brasília-DF, Brasil.E-mail: mpnery@yahoo.com.br
}

dos sujeitos aprovados e dos que não fazem parte do sistema dessa ação afirmativa; compreender as implicações dos sentimentos, dos significados e dos processos identitários encontrados na sociodinâmica desses sujeitos; e analisar as influências das interações afetivas em um processo de inclusão socioracial. Partimos da hipótese de que o processo de inclusão socioracial efetivamente ocorre quando os sujeitos que dele participam direta e indiretamente reorganizam projetos dramáticos, no sentido de produzir status sociométricos que favoreçam a integração social dos sujeitos aprovados pelo sistema de cotas no vestibular. Consideramos que a explicitação da afetividade resultante da experiência da política inclusiva pode produzir novas percepções de si e do outro (identitárias), mobilizar a consciência política, elucidar as significações nas interações e motivar ações que efetivem a inclusão racial. 


\section{$O$ contexto das cotas para negros nas universidades}

\section{Histórico}

Na década de 1960, nos Estados Unidos, a partir dos movimentos pelos direitos civis, surgiram as primeiras idéias sobre affirmative action como um dos caminhos para se atingir a justiça racial distributiva e compensatória. Enquanto isso, no Brasil, os acontecimentos que favoreceram a criação dessas políticas para negros estavam em seus primórdios, dentre eles: os estudos mais especificados sobre a desigualdade racial no país, realizados por vários institutos de pesquisa, desde os anos 1970; a promulgação da Constituição de 1988; o fortalecimento do movimento negro; e em 2001, o reconhecimento mundial do racismo no Brasil pelo governo de Fernando Henrique Cardoso na Conferência Mundial de Combate ao Racismo, Discriminação Racial, Xenofobia e Intolerância Correlata (Guimarães, 2002).

A partir de 2000 a sociedade civil, pela via principalmente da Universidade do Estado do Rio de Janeiro (UERJ) e da Universidade de Brasília (UnB), incrementou a luta em prol das políticas afirmativas raciais. A política afirmativa é um conjunto de medidas públicas ou privadas, dentre elas o sistema de cotas,

de caráter compulsório, facultativo ou voluntário, concebidas com vistas ao combate à discriminação racial, de gênero e de origem nacional, bem como para corrigir os efeitos presentes da discriminação praticada no passado, tendo por objetivo a concretização do ideal de efetiva igualdade de acesso a bens fundamentais, como a educação e o emprego (Gomes, 2001, p. 40).

\section{Correntes de pensamento sobre noções de raça e cotas para negros}

As noções de raça e a especificidade do racismo no Brasil levam a uma séria polêmica principalmente em relação ao sistema de cotas para negros. Embora saibamos que a noção de raça, em termos biológicos, está totalmente derrubada pelas ciências (Gould, 1981/1999; Jacquard, 1978; Langaney, 1988), muitos cientistas sociais defendem que as idéias de raça e de classificações sociais dominam as relações humanas e grupais, como um artifício de poder na sociedade (Carvalho \& Segato, 2002; Guimarães, 1999; Santos, 2007). Esta polêmica gera duas correntes de pensamento.

Alguns intelectuais afirmam a imprescindibilidade das cotas como uma das políticas para a diminuição do racismo e da histórica desigualdade racial no país, dentre eles: Carone e Bento (2002), Carvalho e Segato (2002), Gomes (2001), Guimarães (1999, 2002), Munanga (1996, 1999), Queiroz (2004), Santos (2007) e Santos e Lobato (2003). Em síntese, retiradas as especificidades de cada autor, afirma-se que dentro do processo sócio-histórico brasileiro, a trajetória social do negro segue fluxo sem que a cor seja responsabilizada.

A corrente opositora, com poucas diferenças entre os autores, afirma que esta política não produz a real distribuição de renda, por não atacar a base dos problemas brasileiros, a saber, a desigualdade social, e pode, também, produzir mais discriminação racial. Pertencem a esta corrente, por exemplo: Azevedo (2004), DaMatta (1997), Fry (2005), Kamel (2006), Maggie (2001), Maio e Santos (2005), Reis (1997).

Demo (2007) sustenta que a maior missão da educação é tirar o sujeito de sua pobreza política. Para o autor, há o risco do efeito de poder no sistema de cotas para negros e outras minorias ingressarem nas universidades públicas, principalmente se não houver a concepção e o controle dessas políticas por parte dos interessados (Demo, 2003a, 2007). Efeito de poder é o resultado de uma política pública ou social que, em vez de emancipar os interessados, os marginalizam ainda mais e contribuem para a manutenção do status quo da sociedade (Demo, 2003b).

\section{Referencial teórico}

Moreno (1959/1974) foi o criador da Socionomia, ciência que estuda os grupos, as relações intergrupais e a articulação entre o individual e o coletivo. Na teoria moreniana, são fundamentais para o entendimento do ser humano em situação, os conceitos de papéis sociais, vínculo, grupo e co-inconsciente. Moreno (1984) afirma que o ser humano se revela e se estrutura por meio da ação, que é uma resposta totalizadora ao ambiente físico ou social, na qual estão presentes os atributos da subjetividade (por exemplo, cognição, atitude, história pessoal e afetividade) e os atributos da intersubjetividade (por exemplo, papéis sociais, tipos de vínculo, comportamentos interacionais, contexto, cultura e momento).

Moreno (1984) considera que o estudo dos papéis sociais abre ampla margem para a compreensão do indivíduo na sociedade, para o desenvolvimento de sua subjetividade e processos intersubjetivos. Nesse sentido, os papéis sociais são uma "forma de funcionamento que o indivíduo assume no momento específico em que reage a uma situação específica, na qual outras pessoas ou objetos estão envolvidos" (p. 27). Toda cultura se caracteriza por um conjunto de papéis impostos, com grau variado de sucesso, aos seus membros, assim, "o papel é uma unidade da cultura" (p. 29).

Há, portanto, uma interação entre ego e papéis, em um movimento integrado, no qual a história de vida e o aprendizado da cultura e da sociedade compõem os papéis, possibilitando as interações complexas entre personalidades e culturas dentre dois ou mais indivíduos. A teoria dos papéis pressupõe uma concepção sociopsíquica e cultural de personalidade: "personalidade é uma função de 'g' (genes), 'e' (espontaneidade), 't' (tele) e 'm' (meio)" (Moreno, 1984, p. 102). A espontaneidade ou fator "e" é "uma aptidão plástica de adaptação, mobilidade e flexibilidade do eu" (p. 144), tratase de um fator sociogenético que catalisa a criatividade e é responsável pela sobrevivência do ser humano em um mundo aberto e em constante mudança.

Quando falamos de ação, papéis sociais, cultura e personalidade, tentamos buscar algo que enrede todos esses 
fios em um tecido chamado vínculo, grupo e sociedade. Em Moreno (1972, 1959/1974), a afetividade é o núcleo gerador das redes sociais, ou seja, ela direciona e motiva o ser humano para a formação dos vínculos. Moreno (1972) observou que "quaisquer que sejam as forças sociais que compelem os indivíduos e grupos à migração, quando o comportamento deles amadurece para fazer escolhas e tomar decisões, estas assumem a forma de atrações e repulsas, reveladas pelos intercâmbios afetivos" (p. 376).

Esta constatação foi sistematizada por meio da sociometria, um tipo de microssociologia, especializada em compreender, por meio de métodos e testes sociométricos, os padrões afetivos que organizam os grupos sociais e as características das correntes psicossociais da população, uma infra-estrutura psicossociológica inconsciente. Moreno criou o teste sociométrico, utilizando critérios de escolhas, que são as motivações para os agrupamentos, convivências, realizações de tarefas ou complementação de papéis sociais. As escolhas demonstram as afeições espontâneas, os sentimentos, as atrações, rejeições, indiferenças e afinidades entre os indivíduos e os grupos. Estes critérios dão o momentum do grupo sociometricamente definido e é, na microssociologia, o que as normas e os padrões sociais são na macrossociologia.

Os testes e as observações sociométricas (posições afetivas do indivíduo no grupo) de Moreno isolaram o fator tele do plano social, como a mais simples unidade de sentimentos medida de um indivíduo a outro, que mantém a constância de escolhas em padrão grupal. A principal definição de Moreno (1984) a respeito de tele é: "fator sociogravitacional que opera entre indivíduos, induzindo-os a formar relações de par, triângulos, quadrângulos, polígonos etc., e mais positivas ou negativas, do que por acaso (...) tele é termo derivado do grego e cujo significado é 'longe' ou 'distante'”' (p. 135).

Para o autor, trata-se de um fator eminentemente social "tele é empatia recíproca" (Moreno, 1972, p. 62). As contribuições e contradições conceituais, sobre tele de Moreno, levaram às revisões socionômicas do conceito (Aguiar, 1990; Levy, 2000; Lima, 1999; Nery, 2003; Perazzo, 1999). Nery (2003) concebe tele como o fator sociopsíquico articulador de todas as áreas psíquicas para o estabelecimento dos vínculos, dentre elas, a afetividade, a inteligência, a memória, a percepção, a cognição e a espontaneidade. Aguiar (1990) afirmou que "quando se tenta descrever o evento tele, o que se tem, no nível meramente fenomênico, é a articulação criativa entre parceiros de um mesmo ato (...). Nesse sentido, tele é co-criação" (p. 98). Este autor criou o conceito projeto dramático, na tentativa de ampliar o termo critério sociométrico para a realização de escolhas presentes nas relações humanas. Projeto dramático seriam os critérios de escolhas que abrangem o teste sociométrico, a cena a ser dramatizada em um Psicodrama e o objetivo relacional de qualquer vínculo na vida. A partir desse conceito, Aguiar desenvolve a sociometria dos vínculos cotidianos.

Segundo Perazzo (1999), a configuração sociométrica de um vínculo é instável, pois o campo social exige reformulações constantes dos projetos dramáticos manifestos e latentes. É necessário que se redirecionem as ações conjuntas, nas tentativas de encontrar o equilíbrio da dinâmica relacional e de se evitar ou resolver os conflitos decorrentes das incongruências. Esse processo depende do fator tele atuando nas relações e da espontaneidade-criatividade de seus integrantes.

Ao caminhar para a sociometria do cotidiano, Aguiar (1998) e Perazzo (1999) afirmam que, na interação grupal, os indivíduos vivem algo além de um teste, ou seja, têm uma vivência sociométrica contínua, por meio dos projetos dramáticos. Neste sentido, os projetos dramáticos são os "critérios que orientam não apenas as escolhas sociométricas, mas também a forma como se estruturam as relações interpessoais (...) que se estabelecem em função de objetivos que são comuns porque intercomplementares" (Aguiar, 1998, p. 149).

\section{Método}

Consideramos esta pesquisa como estudo de caso, por buscar conhecer o sujeito na situação concreta, na sua experiência, na sua vida, tentando retratar, o máximo possível, o dinamismo da situação em seu acontecer natural (Stake, 1995). O acesso ao campo deu-se por meio de contatos com pessoas que implantaram o sistema de cotas na UnB, e da realização de seis sociodramas-pilotos (do $1^{\circ}$ semestre de 2003 até o $2^{\circ}$ semestre de 2006, com um total de 132 estudantes) (Nery \& Conceição, 2005, 2006a, 2006b, 2007).

\section{Participantes}

Os sujeitos do sociodrama foram cinco estudantes, com idades entre 20 e 23 anos, sendo quatro do sexo masculino e um do sexo feminino, a renda familiar média do grupo foi de $\mathrm{R} \$$ 6.000. Os estudantes se declararam: quatro de cor branca e um de cor negra e entraram na universidade através do sistema universal de vestibular, a partir da implantação da política. Nenhum estudante que entrou pelo sistema de cotas compareceu ao evento. Em função deste fato, as pesquisadoras decidiram voltar ao campo e realizar entrevistas. Os sujeitos das entrevistas foram: três estudantes do sexo feminino e um funcionário de uma organização não-governamental (ONG), que se propôs a prestar apoio aos estudantes do sistema de cotas na UnB; todos se declararam negros, com idades entre 21 e 28 anos, e não declararam a renda familiar. Os três estudantes entraram pelo sistema de cotas, já o funcionário tinha pós-graduação realizada na UnB.

\section{Instrumentos}

O sociodrama é um método de pesquisa qualitativa, com a característica da intervenção socioterapêutica (Nery, Costa, \& Conceição, 2006). Marra e Costa (2004) concluem que o sociodrama é um método que se coaduna com a pesquisaação, segundo as autoras, a pesquisa-ação se fundamenta, tal qual a Socionomia, epistemologicamente nos grupos, nas comunidades e na dimensão relacional. No sociodrama, os sujeitos dão vida aos personagens latentes que dinamizam e desvelam os estados co-concientes e co-inconscientes 
(Moreno, 1983). Esses estados fornecem ao grupo dinâmicas e características que lhe são peculiares. O método sociodramático visa ao tratamento de síndromes culturais coletivas e à co-criação.

\section{Procedimentos}

Primeiramente procedemos à formação e treinamento da equipe de pesquisa para a realização do sociodrama do estudo. A primeira tentativa de realização ocorreu no dia 29 de outubro de 2005, mas não foi levado a cabo, por ninguém ter comparecido. Finalmente no dia 26 de maio de 2006 realizamos o sociodrama da pesquisa. Utilizamos, para registro, duas filmadoras, colocadas em dois cantos da sala, e cinco gravadores. As filmadoras foram manejadas conforme as localizações dos participantes e as cenas do sociodrama, e os gravadores foram posicionados diante das pessoas, no momento de suas falas. Na dramatização, a cena escolhida foi a do resultado do vestibular, no qual foi implantado o sistema de cotas para o ingresso de negros na universidade. O sociodrama durou 1 hora e 45 minutos, seguindo estas fases: (a) aquecimento, interação inicial dos participantes, com debates intensos sobre o sistema de cotas e como ele interferiu na vida de cada participante e escolha de cena para ser dramatizada; (b) dramatização da cena, com uso de técnicas de ação; (c) compartilhar sobre os sentimentos e percepções vividos no evento. As entrevistas foram semi-estruturadas, enfocando os objetivos do estudo.

No que tange aos cuidados éticos, a pesquisa foi aprovada pelo Departamento de Psicologia Clínica e Cultura da Universidade de Brasília, mediante apropriação da ética em pesquisa por parte dos pesquisadores e da elaboração do Termo de Consentimento para os participantes. Cabe salientar que os participantes do sociodrama foram informados do sigilo em relação às suas identidades, com assinatura do Termo de Consentimento.

\section{Análise de dados}

A análise dos dados foi realizada em dois momentos: primeiramente houve um ordenamento e classificação. Segundo Minayo (2006), a ordenação dos dados engloba as transcrições de fitas e vídeos, releitura do material, organização dos relatos, documentos e observações dos dados em classificação prévia, de acordo com a proposta analítica. É um processo de interação intensa com as informações obtidas na pesquisa. O material empírico sobre o tema é visto em conjunto, como um corpus a ser analisado tecnicamente. Assistimos exaustivamente ao vídeo e ouvimos diversas vezes as entrevistas. Fizemos, conforme proposta da autora, anotações de nossas impressões, na busca da coerência interna das informações. Em segundo lugar, procedemos à análise de conteúdo proposta por González Rey (2005), centrada nos indicadores para a construção de zonas de sentido, principalmente das interações afetivas e atitudinais entre estes estudantes. Zonas de sentido são construções teóricas que tornam inteligíveis espaços de realidades outrora ocultos ou desconhecidos (González Rey, 2005).
A cena mais escolhida pelos grupos, durante o período dos sociodramas pilotos e no sociodrama para esta pesquisa foi o resultado do vestibular em que se implantou o sistema de cotas, de onde emergiram conflitos entre os que passaram por cotas e os que não conseguiram ingressar devido à implantação do sistema.

\section{Resultados e Discussão}

Detectamos três zonas de sentido principais, conforme sintetizamos neste artigo.

\section{Primeira zona de sentido: dinâmica afetiva na interação cotistas $e$ universalistas}

Nesta zona de sentido descrevemos a afetividade encontrada nas interações entre os participantes do sociodrama e detectada nas entrevistas. A dinâmica afetiva grupal é a emocionalidade que compõe as crenças, atitudes e comportamentos do grupo (e de seus subgrupos) na experiência da competição social. Esta dinâmica fundamenta os projetos dramáticos e dinamiza a sociometria do grupo.

A dinâmica afetiva do grupo dos cotistas (e de estudantes negros) preponderante é a necessidade de provar bom desempenho acadêmico para ser reconhecido, devido ao sentimento ou experiência do preconceito gerado pelas cotas, que o perturba em sua vida na universidade. Esta dinâmica está presente ao longo do sociodrama e na cena mais escolhida pelo grupo no sociodrama para o presente estudo (e também nos sociodramas-pilotos): o resultado do vestibular em que se implantou o sistema de cotas, de onde emergiram conflitos entre os que ingressaram por cotas e os que não conseguiram fazê-lo devido à implantação do sistema. Em todos os contextos do sociodrama e nas entrevistas, há diálogos e interações entre participantes e personagens que expõem esta dinâmica.

Por exemplo, no sociodrama, João, único participante negro, se posicionou como porta-voz do estudante negro e do estudante cotista, tanto no contexto grupal quanto no contexto dramático, ao fazer o papel sociodramático de Negro universalista. No início, quando a maioria dos participantes expôs a opinião em relação às cotas como um benefício para os negros, João expressa, gesticulando e em voz alta: "Então, essa sensação de privilégio, de não merecimento, elas estão muito relacionadas. Muitas vezes, o estudante negro se sente impelido a ter que provar suas capacidades, provar que é capaz".

E continua sendo estimulado neste estado emocional até se expor catarticamente, no meio da dramatização:

Eu me sinto... Ter que provar para as pessoas a minha capacidade é algo que me irrita, é algo que me frustra e me incomoda constantemente. Ter que acordar e mostrar, mais uma vez, estou aqui é merecimento, não é presente, não é nada. Estudei e estou aqui! (Personagem Negro universalista) 
Nery, M. P., \& Costa, L. F. (2009). Afetividade e sistema de cotas.

Sérgio também capta da alma do estudante cotista esta crença, ao desempenhar psicodramaticamente o personagem Cotista. Ele é um dos membros do grupo que foi aceito por transferência, na época do segundo vestibular com cotas.

Eu... Me sinto feliz, porque apesar de tudo, superei e precisava superar para conseguir entrar, mesmo que fosse pelo sistema de cotas. Quero agarrar esta oportunidade, o máximo possivel, para fazer valer a pena! Para fazer funcionar e funcionar e outras pessoas terem esta oportunidade, para, exatamente, no futuro não precisar mais ter destas cotas para ter uma justiça. (Personagem Cotista)

Neste momento, Sérgio, embora desfavorável às cotas, ao viver este papel psicodramático se torna um representante virtual deste grupo social, pois nenhum cotista compareceu ao sociodrama da tese. As entrevistas contribuíram para confirmar dados do sociodrama e complementar suas informações, como, por exemplo, sobre a autocobrança, a estudante nos diz:

Aqui dentro da universidade, um dos sofrimentos do cotista é que você tem que provar que você pode, sabe? Que você pode... Que você está aqui e conseguiu a vaga por mérito seu, sabe? (...) Tem esta história da nota de corte menor... Você tem que ficar provando que você é bom, que você pode, que você pode estudar tanto quanto o universalista, sabe? (Entrevistada cotista Joana)

A dinâmica afetiva dos estudantes universalistas é a indiferença e o descaso em relação às causas raciais, o que gera um individualismo fortalecedor de discursos dominantes em relação aos privilégios sociais. Neste trecho, Adriana, reprovada em dois vestibulares em que se implantou o sistema, se firma em suas idéias, apoiadas por outros participantes. $\mathrm{Na}$ dramatização, ela desempenha o papel sociodramático de Candidata reprovada: "Mas, então... no meu caso, por exemplo. Uma pessoa que, dentro das cotas, tirou 60 passou e eu que tirei cento e poucos não passei. Essa pessoa não foi beneficiada? Entendeu?".

Surgem dispositivos de relações de poder e da discriminação que emerge do sistema de cotas, principalmente o da negativa de aprofundar sobre a questão racial. No contexto do debate inicial, Marcos, estudante universalista aprovado no vestibular anterior em que se implantou o sistema de cotas, emerge como o solitário crítico social, único solidário a João.

João: Minha cena é sentimento de depreciação que a pessoa sente por dizerem que recebeu beneficios por ser cotista.

Marcos: Racismo.
Sérgio: Não é racismo.

Marcos: Sim, é.

Sérgio: Não quero entrar no mérito desta questão. Mas, não acho que é racismo!

Marcos: Acho que deve entrar no mérito da questão!

Sérgio: Acho que qualquer grupo social, por exemplo, a mesma coisa que fizesse com pessoal de colégio público. Em vez de ser cotas para negros, fosse para ensino público, o pessoal passaria pela mesma coisa. Não ia ser racismo, ia ser por classe: "Ah você veio do ensino público, né? Hã, hã!! Então, não é racismo, neste ponto.

Entrevistadora (diretora do sociodrama): Você não concorda? Qual seu argumento?

Marcos: $O$ meu argumento é quando você faz uma política de cotas você tem que analisar uma dicotomia racismo-anti-racismo. O que ele está colocando ai seria um anti-racismo, mas na verdade se configura como racismo. Este anti-racismo que o colega colocou está dentro de uma mentalidade de embranquecimento da população... E o quê da questão da política de cotas é valorizar o sentimento de negritude, valorizar uma estética negra, reparar um mal social histórico.

Detectamos também a dinâmica afetiva intergrupal, composta por processos afetivos que geram crenças e atitudes que interferem no exercício de poder. A dinâmica afetiva intergrupal explicita os projetos dramáticos sintetizados em: (a) subgrupo dos desfavoráves às cotas: "Estamos coesos em nossos entendimentos, não precisamos mudá-los; não somos racistas e não precisamos ampliar nossa consciência racial"; (b) subgrupo dos favoráveis às cotas: "É preciso que vocês percebam que estão discriminando, é preciso que vocês nos vejam, nos reconheçam, nos valorizem em nossa identidade e lutas".

Os indicadores retratam a dificuldade de reformularem os projetos dramáticos e cada subgrupo entra em uma competição sociométrica, prevalecendo a hostilidade. No início da dramatização, por exemplo, na cena do resultado do vestibular, solicitamos uma "imagem", técnica psicodramática em que o diretor pede para demonstrarem com o corpo e sem movimento como os personagens se sentem na situação. Nesta "imagem", a expressão corporal dos personagens reforçou os indicadores da competição sociométrica, pois o Cotista e o Negro universalista ficaram de pé, cabisbaixos, com expressão séria, braços dobrados e mãos em punho, indicando a vitória de terem passado no vestibular, mas 
também insinuando uma posição de confronto. A personagem Branca cotista (que fraudou o sistema de cotas) sorriu ironicamente e expressou sua vitória, colocando uma mão na cintura e elevando a outra em punho. O personagem Branco universalista ficou de pé com expressão tranquila, depois de demonstrar desconfiança em relação à capacidade do negro e do cotista, ele olhou para a Candidata reprovada. A personagem Candidata reprovada se sentou e ficou com a cabeça baixa, na tentativa de dar expressão corporal a sua tristeza. Um pouco antes da imagem, houve, em síntese, este diálogo dramático:

Personagem Branco Universalista: E você, tirou quanto?

Personagem Negro Universalista: Eu? 240.

Personagem Cotista: Ué, a nota de corte é 60, estou apto para entrar na universidade! Você está dizendo que não estou apto?

Personagem Branco Universalista: Não sei dizer... Tem que ver agora, se você vai conseguir acompanhar as matérias.

Em seguida, o descaso da personagem Branca Cotista, que frauda o sistema e desqualifica as causas e a identidade racial.

Personagem Negro Universalista: Como você entrou pelo sistema?

Personagem Branca Cotista: Uai... Sou preta! (...) Eu entrei como preta.

Personagem Cotista: Espera aí, você não é preta, não.

Candidata reprovada: Quem deveria passar e é sério, não passa por causa das cotas.

Negro Universalista: Você se sente negra?

Branca Cotista: Não me sinto negra, não... Mas foi uma oportunidade... Eu tinha esta chance, podia me declarar negra... Afinal, o Brasil é um país de mestiços mesmo!

Neste sociodrama, as configurações sociométricas predominantes, produzidas pela dinâmica afetiva intergrupal, foram as de isolamento do negro e de afastamento do tema racial. Esta sociometria é demonstrada nos indicadores do não prosseguimento à fala do negro ou de quem o apóia, na persistência em manter os discursos dominantes e na dificuldade de inversão de papéis (técnica psicodramática em que os participantes se imaginam no lugar do outro) por parte dos desfavoráveis às cotas. Por exemplo, a maioria insistiu no argumento da meritocracia, como podemos destacar: "A indignação não está na cor, mas na nota de corte abaixo. A questão do mérito acadêmico. No vestibular... só passam aqueles que obtiveram as maiores notas" (Alberto).

Alberto é o estudante universalista aprovado no vestibular anterior à implantação do sistema de cotas para o ingresso de negros na universidade. A dinâmica afetiva intergrupal apresenta indicadores relacionados a mecanismos presentes no exercício do poder, como por exemplo, a "antiempatia" ou um movimento atitudinal do sujeito em direção contrária ao desenvolvimento empático, para que ele se fortaleça em suas ideologias. Vejamos a síntese destas expressões emocionais do personagem Negro universalista, quase no final da dramatização, denunciando o aprisionamento dos participantes em suas ideologias:

Meu sentimento é de bastante, assim, raiva, sabe? Raiva por vários motivos. Assim... Por mais uma vez ter que ter posto a minha capacidade em jogo, entende? (...) Se eu quero entender realmente o que está acontecendo, eu tenho que pensar no negro de uma forma geral... Então, pouco importa, na verdade, pouco importa se ele tirou uma nota menor que ela, entendeu? Ou maior que ela. Ou se eu passei no universal. Pô, mais uma vez o negro é posto para provar seu mérito... Vão perguntar de novo, qualquer outra coisa que vai estar dentro da esfera do mérito... Vão chegar e dizer assim: mas será que este palestrante é bom? Não é daquela turma de cotas? (...) E não sei o que... o importante é estar participando, o importante é estar crescendo. (Personagem Negro universalista)

Este grito para ser visto, porém, não captou o apoio do grupo, sendo um indício de antiempatia. No exercício de poder, a indisponibilidade em compreender o outro é uma das armas para a manutenção dos privilégios sociais.

\section{Segunda zona de sentido: processos identitários dos cotistas e universalistas}

Nesta zona de sentido tentamos ampliar a compreensão de como a afetividade compõe os processos identitários. No desenvolvimento da identidade dos papéis de cotista e de universalista, em um contexto inclusivo, detectamos indicadores que compõem os seguintes processos identitários: paradoxo identitário e as experiências da identidade radical, da identidade oculta e da identidade flexível.

O paradoxo identitário é um mecanismo social, vivido por indivíduos e grupos discriminados, que congrega tanto o desejo quanto o temor de expor a identidade, ocasionando perturbações em seu processo político de organização social. Este mecanismo também se compõe das ambivalências na vivência das identidades sociais. 
Eu, ao mesmo tempo em que me sinto feliz, porque apesar de tudo, superei e precisava superar para conseguir entrar, mesmo que fosse pelo sistema de cotas... Ao mesmo tempo, eu sinto tristeza por uma colega que teve uma nota superior (e não passou). Mas, aí, entra muito em choque o meu egoísmo de querer ser bem sucedido na vida e toda minha raiva das situações que passei no passado, tanta discriminação e tudo mais! Mas desta vez eu superei. E indignação, em relação ao meu colega, também, né? (Personagem Cotista)

No confronto entre os participantes, a ideologia brasileira do paraíso racial esteve muito presente e os personagens Candidata reprovada e Branca cotista banalizam a questão, "Quem é negro neste país?", que hipnotiza opositores e favoráveis às cotas. Neste microcosmo, observamos que os papéis de cotista e de universalista revigoram os jogos de poder na sociedade, sintetizam os fatos culturais e consolidam a história. Tornam-se papéis históricos (Naffah Neto, 1997), que reforçam a tipicidade do racismo brasileiro de ser cordial e invisível (Carone \& Bento, 2002; Guimarães, 1999).

$\mathrm{Na}$ entrevista, a identidade radical das cotistas e do funcionário da ONG se desvela no desejo do confronto. No sociodrama, a identidade radical esteve presente na hostilidade entre os subgrupos, na raiva do negro e na ênfase ao sofrimento pessoal. No meio da dramatização da cena do resultado do vestibular, retiramos uma foto da filmagem que mostra o Negro universalista expressando seus sentimentos em reação a toda a discriminação derivada do sistema de cotas exposta ao longo do evento. Ele olha com raiva para o grupo, coloca uma mão em punho, movimenta-a energicamente e expressa intensamente suas emoções. Os participantes olham atentamente para ele, porém não estabelecem diálogo a partir desta fala. E contesta, em síntese:

Sempre um momento histórico, muitas vezes de transformação, que acontece? Ele acarreta dúvidas, entendeu? É o mesmo sentimento de culpa que o jovem negro lá, acho que em 53 ou 63, quando foi posto em escolas brancas, todo mundo chegava e falava assim: "Mas este negro ai que estudou 10 anos em escola pública de negros aqui nos Estados Unidos, que o ensino é pior, vai estar agora na minha sala, abaixando o nível!" Você sabe lá se este negro é capaz ou não? (...) Raiva de tá tendo que viver um negócio assim. É estar tendo que ser subjugado ou depreciado, muitas vezes. (Personagem Negro universalista)

No processo inclusivo há grupos ou momentos de experiências em que os indivíduos ocultam a identidade. Este ocultamento ocasiona, por exemplo, a não participação dos cotistas nos eventos relacionados à questão racial e o não usufruto de apoios psicossociais e acadêmicos. Nesse sentido:
Já tivemos 20 vagas para estágio e são 1.800 cotistas... Nossa... Têm muitas pessoas para essas vagas... Era para preencher todas as vagas. Mas elas ficam ociosas. As pessoas não procuram. E olha que a gente mostra pela internet, pelos e-mails. Já pregamos várias vezes cartazes, sabe? Se eles esquecem falamos de novo... E, também, os cotistas não participam de eventos, como ocorreu no seu sociodrama. (Entrevistada cotista Nilda)

Há universalistas que ocultam sua identidade, como detectamos no sociodrama:

Mas, conheço muitas pessoas que a única preocupação é com o estudo, com as metas próprias: o meu objetivo é passar, passei. Então, não troca papéis. Não consegue ver a história, o que aconteceu antes e o que acontece depois. Ele acaba, realmente, se isolando do resto. (Participante Alberto)

Também encontramos momentos em que indivíduos ou grupos tentaram flexibilizar sua identidade para melhorar as relações no contexto inclusivo.

Eu me sinto triste. Particularmente com uma frustração pessoal de mais uma vez não ter passado... E, o pior, é saber que têm pessoas que tiveram rendimento abaixo de mim, sobre o mesmo objeto, $e$ vão estar no curso, vão estar adiantando a vida. (Personagem Negro universalista, ao inverter papel com a candidata reprovada)

Sérgio, no compartilhar, depois de viver o papel do Cotista, também demonstra o quanto a aprendizagem psicodramática lhe possibilitou flexibilizar sua identidade de universalista.

\begin{abstract}
Meu personagem (Cotista)... Por meio dele, vi que tenho que agarrar esta oportunidade, certo? Fiz uma opção mais grata... Mas... Veio a culpa, realmente: "Pô, eu passei com uma nota menor que a dela, então"... Pesou muito para o meu personagem. Imagino o que seria a vida acadêmica de uma pessoa o tempo todo sofrendo esta culpa e... Sofre a discriminação por ser de cota, então... As pessoas discriminam... Então, imagina pelo sistema de cotas... Imagino o aluno, nesta situação, deve ser muita barra. (Participante Sérgio)
\end{abstract}

Diante disso, nota-se que a flexibilização da identidade é fundamental para o sucesso de qualquer processo inclusivo, pois contribui para o diálogo empático, depois de se evidenciarem as identidades presentes. 


\section{Terceira zona de sentido: cotas, discriminação e universidade}

$\mathrm{Na}$ terceira zona de sentido, detectamos a discriminação resultante do sistema de cotas raciais. Neste estudo, a conexão das dimensões afetivas, cognitivas, atitudinais e de ação intergrupal revelaram preconceitos que acirram a discriminação no processo de inclusão racial, dentre eles: o cotista é visto como um beneficiado e privilegiado pela política afirmativa; é julgado como uma nota de corte inferior; ele e o estudante negro são considerados incapazes, depreciados em seu mérito, não merecedores de estarem na universidade; eles são desqualificados em sua identidade racial e em suas causas e sofrem o isolamento, a indiferença e as ambivalências na afetividade intergrupal.

Esta discriminação provoca tanto no cotista quanto no estudante negro as sensações, principalmente, de ficarem de fora, de serem excluídos, promovem a autocobrança de terem que provar que são capazes e a cobrança de terem excelente desempenho acadêmico.

Ainda houve indicadores relativos ao mecanismo afetivo presente neste peculiar processo discriminatório: a ambivalência na afetividade intergrupal. Os participantes desfavoráveis expressaram afeto (amor aos negros), atitudes que demonstrassem uma autodefesa e uma defesa ao ataque de ser racista, criticaram os preconceitos aos cotistas e até um deles se imaginou no lugar do estudante negro cotista, na dramatização. Porém, nestes sentimentos e condutas havia ambivalências e contradições, pois não se coadunavam com as atitudes de indisponibilidade para se aprofundar sobre a história da desigualdade racial; minimizar as questões raciais; qualificar outros tipos de preconceitos como mais danosos do que a discriminação racial e de desviar questões coletivas para o âmbito individual, inclusive por parte da equipe de pesquisa.

Observamos indicadores relacionados a não organização política do estudante. "Politicidade é a habilidade de saber pensar e intervir, de participar e conduzir a história" (Demo, 2002). Porém está tão enfraquecida entre os estudantes, a ponto de criarmos o termo "apoliticidade", para caracterizar, pelo menos no que se refere à inclusão racial, o desinteresse em desenvolver a consciência crítica e a participação ativa neste momento histórico, tornando-o uma oportunidade efetiva de transformação social.

As pessoas têm muitos limites, acham que não vão usar isso (sociodrama sobre cotas) na vida delas, não vai ser útil ou mudar a vida delas. Não querem ficar falando de cotas. Não estão interessadas em participar desse tipo de evento, não acham relevante. Houve desinteresse. (Entrevistada cotista Joana)

Quanto ao universalista, sua apoliticidade foi demonstrada, principalmente na busca de manutenção dos privilégios sociais. Inferimos que esta apoliticidade pode gerar o "efeito de poder" das cotas raciais (Demo, 2003a).
Contraditoriamente, os entrevistados nos apontam caminhos, como o exemplo:

O que favorece a inclusão racial é o diálogo com o professor e com alunos... Isso estimula mais... Alguém te reconhece sem discriminação e te incentiva a estudar.. Você percebe que não está sozinho, tem alguém que está te ajudando. (Entrevistada cotista Nilda)

Nesta pesquisa, confirmamos estudos de Oliven (2007), Queiroz (2004), e de Santos (2007): ao se subjugar ao preconceito externalizado ou silenciado, muitos cotistas se enfraquecem em sua união e organização política. E trazemos a hipótese de que ao supervalorizar determinadas visões da política racial, muitos estudantes universalistas se unem e se fortalecem socialmente.

Também corroboramos Moreno (1972, 1959/1974) quando afirma que os grupos lutam por uma posição socionômica, não apenas se dividem nas identidades relacionadas às raças, religiões, estados e nações. A hierarquia socionômica nos mostra que há uma competição sociométrica entre os grupos, pois uns são mais atraentes do que outros, influenciando no exercício do poder. Indivíduos e grupos menos atraentes tendem a conquistar, através da força ou de artifícios, o que não lhes é proporcionado pela atração espontânea.

\section{Considerações finais}

Esta pesquisa tentou ir além da polêmica atitudinal em relação às cotas para negros e demonstrar a interferência de processos afetivos (ou sociométricos) nas relações intergrupais nos exercícios de poder presentes na sociedade. A afetividade intergrupal entre estudantes negros, cotistas e universalistas tem a potência de gerar uma discriminação específica que tende a manter o status quo da sociedade. Esta discriminação é construída a partir da indiferença em relação ao cotista (por meio, por exemplo, dos mecanismos da "antiempatia" e das ambivalências afetivas), do descaso em relação à causa racial e da hostilidade resultante da crença da experiência de uma injustiça consequente da política afirmativa.

Quanto à inclusão racial na universidade, vimos que nossa hipótese de pesquisa não foi confirmada. Sociometricamente, tanto o estudante negro universalista quanto o negro cotista predominantemente se sentem discriminados, afastados e isolados. Apesar de, por exemplo, a maioria dos cotistas evitarem participar de eventos relacionados às questões raciais, como o sociodrama, e ocultarem sua identidade, como tentativa de lidar com a discriminação, alguns propõem o diálogo, o debate e a participação como esperança para a saída do silenciamento, da anulação da identidade racial e do sofrimento em sua experiência inclusiva.

Alertamos que a comunidade acadêmica, ao realizar projetos psicossociais específicos e multidiciplinares no sentido 
da inclusão racial efetiva, nos ajudará a lidar com a diversidade, a aprender com as relações intergrupais, no sentido liberador da co-criação, e a evitar o "efeito de poder". Diante deste processo, novas indagações surgem: Qual o papel da Psicologia na vigência de uma política afirmativa? Como contribuir para flexibilizar os processos identitários e para a efetiva inclusão racial? Qual o lugar do imaginário para a produção de conhecimento? Deparamo-nos com a necessidade de aperfeiçoar a análise das informações produzidas em métodos de ação, principalmente na dramatização e de se observar o caráter político deste tipo de pesquisa, em que há a produção conjunta do saber.

\section{Referências}

Aguiar, M. (1990). O teatro terapêutico. Campinas, SP: Papirus.

Aguiar, M. (1998). Teatro espontâneo e psicodrama. São Paulo: Ágora.

Azevedo, C. M. M. (2004). Anti-racismo e seus paradoxos: Reflexões sobre cota racial, raça e racismo. São Paulo: Annablume.

Carone, I., \& Bento, M. A. S. (Orgs.). (2002). Psicologia social do racismo: Estudos sobre a branquitude e branqueamento no Brasil. Petrópolis, RJ: Vozes.

Carvalho, J. J., \& Segato, R. L. (2002). Uma proposta de cotas para estudantes negros na Universidade de Brasilia (Série Antropologia, No. 314). Brasília, DF: Universidade de Brasília. Recuperado em 14 dezembro 2003, de http://www.unb.br/ics/dan/Serie314empdf.pdf

DaMatta, R. (1997). Notas sobre o racismo à brasileira. In A. Sant'Anna \& J. Souza (Orgs.), Multiculturalismo e racismo: Uma comparação Brasil-Estados Unidos (pp. 69-76). Brasília, DF: Paralelo 15.

Demo, P. (2002). Politicidade: Razão humana. Campinas, SP: Papirus.

Demo, P. (2003a). Focalização de políticas sociais: Um debate mais perdido do que a agenda perdida. Serviço Social e Sociedade, 24(76), 93-117.

Demo, P. (2003b). Pobreza da pobreza. Petrópolis, RJ: Vozes.

Demo, P. (2007). Educação: Coisa pobre para o pobre. Educação Profissional: Ciência e Tecnologia, 1, 165-178.

Fry, P. (2005). A persistência da raça: Ensaios antropológicos sobre o Brasil e a África Austral. Rio de Janeiro: Civilização Brasileira.

Gomes, J. B. B. (2001). Ação afirmativa e princípio constitucional da igualdade: $O$ direito como instrumento de transformação social. Rio de Janeiro: Renovar.

González Rey, F. (2005). Pesquisa qualitativa e subjetividade: Os processos de construção da informação (M. A. F. Silva, Trad.). São Paulo: Pioneira Thomson Learning.

Gould, S. J. (1999). A falsa medida do homem (V. L. Siqueira, Trad., 2a ed.). São Paulo: Martins Fontes. (Original publicado em 1981)
Guimarães, A. S. A. (1999). Racismo e anti-racismo no Brasil. São Paulo: Editora 34.

Guimarães, A. S. A. (2002). Classes, raça e democracia. São Paulo: Editora 34.

Jacquard, A. (1978). Eloge de la différence: La génétique et les hommes. Paris: Seuil.

Kamel, A. (2006). Não somos racistas. Rio de Janeiro: Nova Fronteira.

Langaney, A. (1988). Les hommes: Passé, présent, conditionnel. Paris: Colin.

Levy, L. (2000). Integrando diferenças: Possíveis caminhos da vivência terapêutica. São Paulo: Ágora.

Lima, N. B. S. (1999). O processo de cura no psicodrama bipessoal. Revista Brasileira de Psicodrama, 7, 33-49.

Maggie, Y. (2001). Os novos bacharéis: A experiência do movimento do pré-vestibular para negros e carentes. Novos Estudos Cebrap, 59, 193-202.

Maio, M. C., \& Santos, R. V. (2005). Política de cotas raciais, os olhos da sociedade e os usos da antropologia: O caso do vestibular da Universidade de Brasília (UnB). Horizontes Antropológicos, 11(23), 181-214.

Marra, M. M., \& Costa, L. F. (2004). A pesquisa-ação e o sociodrama: Uma conexão possível? Revista Brasileira de Psicodrama, 12, 99-116.

Minayo, M. C. S. (2006). O desafio do conhecimento: Pesquisa qualitativa em saúde. São Paulo: Hucitec.

Moreno, J. L. (1972). Fundamentos de la sociometria. Buenos Aires: Paidós.

Moreno, J. L. (1974). Psicoterapia de grupo e psicodrama. Introdução à teoria e à práxis (A. C. M. Cesarino Filho, Trad.) São Paulo: Mestre Jou. (Original publicado em 1959)

Moreno, J. L. (1983). Fundamentos do psicodrama (M. S. M. Neto, Trad.) São Paulo: Summus. (Original publicado em 1959)

Moreno, J. L. (1984). Psicodrama (A. Cabral, Trad., 3a ed.). São Paulo: Cultrix.

Munanga, K. (1996). O anti-racismo no Brasil. In K. Munanga (Org.), Estratégias e políticas de combate à discriminação racial (pp. 79-111). São Paulo: EDUSP.

Munanga, K. (1999). Rediscutindo a mestiçagem no Brasil: Identidade nacional versus identidade negra. Petrópolis, RJ: Vozes.

Naffah Neto, A. (1997). Psicodrama: Descolonizando o imaginário. São Paulo: Plexus.

Nery, M. P. (2003). Vínculo e afetividade: Caminhos das relações humanas. São Paulo: Ágora.

Nery, M. P., \& Conceição, M. I. G. (2005). Sociodrama e política de cotas para negros: um método de intervenção psicológica em temas sociais. Psicologia: Ciência $e$ Profissão, 25, 132-145.

Nery, M. P., \& Conceição, M. I. G. (2006a). Política racial afirmativa e afetividade na interação intergrupal [Versão eletrônica]. Interação em Psicologia, 10(2), 363-374. Recuperado em 20 maio 2007, de http://calvados.c3sl.ufpr. br/ojs2/index.php/psicologia/article/view/7695/5487 
Nery, M. P., \& Conceição, M. I. G. (2006b). Sociodrama da inclusão racial: Quebrando a inércia. Revista Brasileira de Psicodrama, 14, 105-119.

Nery, M. P., \& Conceição, M. I. G. (2007). Política racial afirmativa: Uma leitura do fenômeno inclusivo na universidade. Educação Profissional: Ciência e Tecnologia, 1, 179-190.

Nery, M. P., Costa L. F., \& Conceição, M. I. G. (2006). O sociodrama como método de pesquisa qualitativa. Paidéia (Ribeirão Preto), 16, 305-314.

Oliven, A. C. (2007). Ações afirmativas, relações raciais e política de cotas nas universidades: Uma comparação entre os Estados Unidos e o Brasil. Educação, 30, 29-51.

Perazzo, S. (1999). Fragmentos de um olhar psicodramático. São Paulo: Ágora.

Queiroz, D. M. (2004). Universidade e desigualdade: Brancos e negros no ensino superior. Brasília, DF: Liber Livro.

Reis, F. W. (1997). Mito e valor da democracia racial. In A. Sant'Anna \& J. Souza (Orgs.), Multiculturalismo e racismo: Uma comparação Brasil-Estados Unidos (pp. 221-232). Brasília, DF: Paralelo 15.

Santos, S. A. (2007). Movimentos negros, educação e ações afirmativas. Tese de doutorado não-publicada, Universidade de Brasília, Brasília, DF.

Santos, R. E., \& Lobato, F. (2003). Ações afirmativas: Políticas públicas contra as desigualdades raciais. São Paulo: DP\&A.

Stake, E. E. (1995). The art of case study research. Thousand Oaks, CA: Sage.

Maria da Penha Nery é Professora Convidada do Instituto de Psicologia da Universidade de Brasília.

Liana Fortunato Costa é Professora Associada do Programa de Pós-graduação em Psicologia Clínica e Cultura do Instituto de Psicologia da Universidade de Brasília.

Recebido: 03/07/2008

$1^{a}$ revisão: $13 / 02 / 2009$

$2^{a}$ revisão: $29 / 04 / 2009$

Aceite final: 11/05/2009 